\title{
Acute traumatic injury of the aorta: presentation, diagnosis, and treatment
}

\author{
S. Rodes Brown ${ }^{1}$, Sasha A. Still ${ }^{2}$, Kyle W. Eudailey², Adam W. Beck ${ }^{3}$, Andrew J. Gunn ${ }^{4}$ \\ ${ }^{1}$ Department of Radiology, ${ }^{2}$ Division of Cardiothoracic Surgery, Department of Surgery, ${ }^{3}$ Division of Vascular Surgery and Endovascular Therapy, \\ Department of Surgery, ${ }^{4}$ Division of Interventional Radiology, Department of Radiology, University of Alabama at Birmingham, Birmingham, AL, USA \\ Contributions: (I) Conception and design: All authors; (II) Administrative support: KW Eudailey, AW Beck, AJ Gunn; (III) Provision of study materials \\ or patients: All authors; (IV) Collection and assembly of data: All authors; (V) Data analysis and interpretation: All authors; (VI) Manuscript writing: \\ All authors; (VII) Final approval of manuscript: All authors. \\ Correspondence to: Andrew J. Gunn, MD. Division of Interventional Radiology, Department of Radiology, University of Alabama at Birmingham, 619 \\ 19th St. S, NHB 623, Birmingham, AL 35294, USA. Email: agunn@uabmc.edu.
}

\begin{abstract}
Despite advances in detection and treatment, acute traumatic aortic injury (ATAI) is associated with high rates of morbidity and mortality. Both physical and hemodynamic forces have been postulated as mechanisms of aortic injury during a traumatic event. For patients who survive the initial injury, rapid detection is critical for diagnosis and procedural planning, which requires a thorough knowledge of both its clinical presentation and the available diagnostic imaging modalities. Radiography, computed tomography (CT), and magnetic resonance imaging (MRI) can each have a role in the diagnosis of ATAI. After stabilization of the patient, the management of ATAI is guided by the severity of injury. Appropriately selected patients with low grade injuries may be managed non-operatively. When treatment is required, there are both open surgical and endovascular options. In current practice, endovascular approaches with stentgraft placement are preferred due to their high clinical success and low rates of complications. Complications from endograft placement can include: endoleak, endograft collapse, infection, endograft failure, and endograft migration. Open surgical repair is now reserved for patients with unfavorable anatomy for endovascular therapies. This review provides a comprehensive overview of ATAI including its epidemiology and demographics, mechanisms of injury, clinical and radiographic diagnosis, treatment options, and posttherapeutic follow-up.
\end{abstract}

Keywords: Trauma; aorta; aortic injury; thoracic endovascular aortic repair (TEVAR)

Submitted Apr 07, 2020. Accepted for publication Jul 24, 2020.

doi: $10.21037 /$ atm-20-3172

View this article at: http://dx.doi.org/10.21037/atm-20-3172

\section{Introduction}

Few mechanisms of injury match the lethality of acute aortic trauma. Despite advances in detection and treatment, as many as $80-90 \%$ of cases are immediately fatal (1). For patients that survive long enough to reach a treatment center, rapid detection and decisive intervention are paramount. Even though catheter-based angiography has served as the gold standard for the diagnosis of acute traumatic aortic injury (ATAI) (2), non-invasive imaging modalities, especially computed tomography angiography
(CTA), have become the primary problem-solving tool in the stable patient prior to endovascular therapy due to its availability, speed, and sensitivity (3-5). Therapeutic options for ATAI include non-operative management, endovascular repair, and open repair. Open repair, even with advances in technique and physiologic support mechanisms, is associated with significant morbidity and mortality (6-8). To this end, endovascular options have emerged as a means to treat ATAI safely (7-11). The purpose of this article is to provide the reader with a comprehensive overview of ATAI. The epidemiology and demographics of, mechanism 
of injury in, diagnosis of, treatment options for, and posttherapeutic follow-up for ATAI will be discussed.

\section{Epidemiology and demographics}

Overall, ATAI is relatively rare, with an estimated occurrence in $1-2 \%$ of trauma patients at level 1 or 2 centers (2). Most ATAI occurs in the setting of motor vehicle collisions (MVCs); thus, patient demographics of ATAI tends to mirror that of MVCs incidence (3). Namely, ATAI patients are more likely to be male with an age distribution correlating with the onset of driving privileges at age 16 and tapering off beyond age 50 (4). Among patients involved in MVCs, ATAI accounts for $16 \%$ of all deaths, which is second only to head injuries (5).

\section{Mechanism of injury}

The exact mechanisms underlying ATAI of the thoracic aorta have been studied extensively, and there are two leading physical theories. The most commonly described physical mechanism is rapid deceleration with the application of either anteroposterior (AP) or lateral forces upon the relatively mobile ascending thoracic aorta. For instance, a change in velocity greater than 20 miles per hour and intrusion of the passenger compartment space greater than 15 inches is a known risk factor for ATAI (6). Further, the vector of these collision forces plays a significant role in determining the likelihood of ATAI. Multiple studies have shown that lateral impact collisions are associated with higher mortality rates $(6,7)$. Regardless, rapid deceleration with either AP or lateral forces cause cardiac displacement and sudden stretching of the aorta, which transmits both torsion and shearing forces to sites of relative fixation, notably the aortic isthmus, aortic root, and diaphragm $(8,9)$. The other major physical theory underlying ATAI is osseous pinch. Here, it is suggested that compression of the aorta between the fixed anterior manubrium and posterior thoracic spine results in transverse laceration at the aortic isthmus $(10,11)$. Of course, direct penetrating injury from rib and thoracic vertebral fractures may also occur.

The leading hemodynamic theory for ATAI of the thoracic aorta is the water-hammer effect $(12,13)$. The water-hammer effect occurs when the abrupt occlusion of non-compressible fluid leads to reflection of high-pressure waves along the vessel wall $(8,9)$. Compression of the aorta at the level of the diaphragm during impact is responsible for this acute increase in intravascular pressure. The pressure wave is further intensified at the aortic arch due to its curvature with pressure values commonly exceeding $2,000 \mathrm{mmHg}(8,9,14,15)$. The ultimate result from these mechanisms of injury is the development of the spectrum of acute aortic injury including isolated intramural hematoma/ intimal disruption, pseudoaneurysm, or complete transection of the aorta, all of which can also result in an associated dissection with true and false lumens (Figure 1).

Regarding ATAI of the abdominal aorta, penetrating trauma is the most frequent cause as blunt abdominal aortic injury is quite rare, comprising less than $1 \%$ of all blunt traumatic injuries (Figure 2) (16). The relative fixation of the abdominal aorta against the vertebral column predisposes it to injury from adjacent vertebral body fractures $(1,17)$. The most commonly involved aortic segments are: infrarenal (67\%), suprarenal (33\%), and extension from a thoracic aortic injury (25\%) (12).

\section{Diagnosis}

\section{Clinical presentation}

Patients that initially survive ATAI are transiently protected from rupture and catastrophic hemorrhage by the aortic adventitia and surrounding mediastinal structures as seen in non-traumatic dissection pathology (1). The collection of blood within the adventitia begins to stretch the tissuea phenomenon that is thought to be responsible for the retrosternal chest pain seen as the most common complaint in patients with ATAI $(3,13,14,18)$. Other common symptoms of ATAI are also secondary to acute aortic expansion and dilation and include dyspnea, cough, referred inter-scapular pain, and hoarseness. Clinical findings can include hypotension, lower extremity pulse deficit, upper extremity hypertension, and evidence of external chest trauma $(14,18,19)$.

\section{Radiography}

The chest radiograph is commonly the first opportunity to evaluate the mediastinal structures for signs of aortic injury. The most commonly reported radiographic findings of ATAI include widening of the mediastinal silhouette to greater than $8 \mathrm{~cm}$ or $25 \%$ of the total thoracic width, loss of aortic contour, rightward deviation of the trachea or nasogastric tube (if placed), and loss of the aortopulmonary window (Figure 3) $(19,20)$. Though these findings are sensitive for aortic injury when present, they are not always 

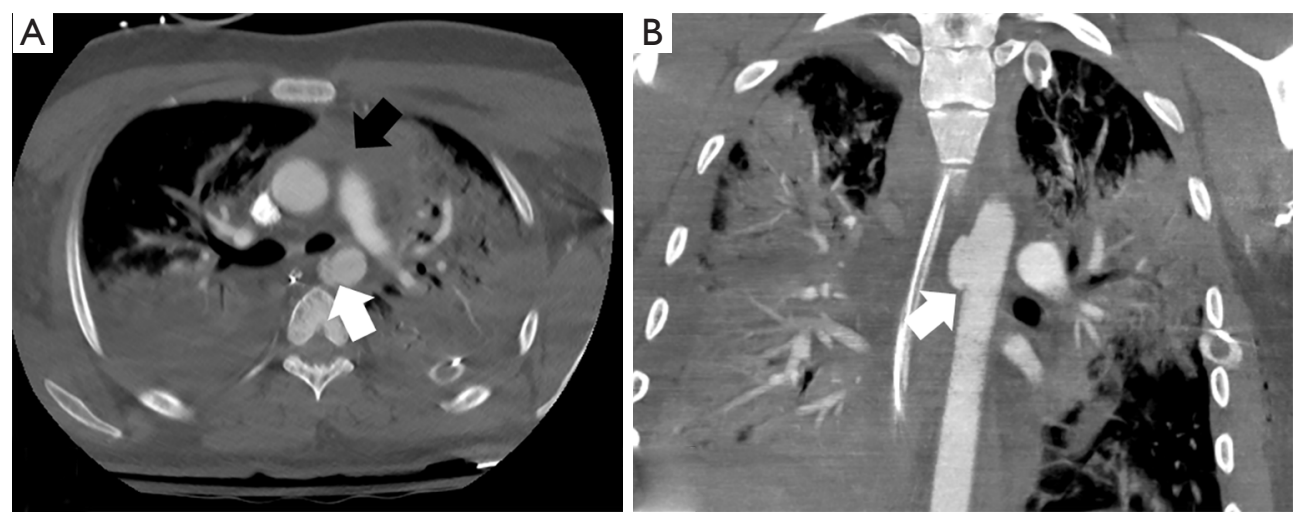

Figure 1 A patient involved in a motor vehicle crash. (A) Axial slice from a contrast-enhanced CT of the chest demonstrates intimal disruption of the descending thoracic aorta (white arrow), a direct sign of thoracic aortic injury. Mediastinal hematoma, an indirect sign of thoracic aortic injury, is also seen (black arrow); (B) coronal reformat image from a contrast-enhanced CT of the chest demonstrates a pseudoaneurysm of the descending thoracic aorta, a direct sign of thoracic aortic injury. A nasogastric tube and left chest tube are seen in both images. CT, computed tomography.
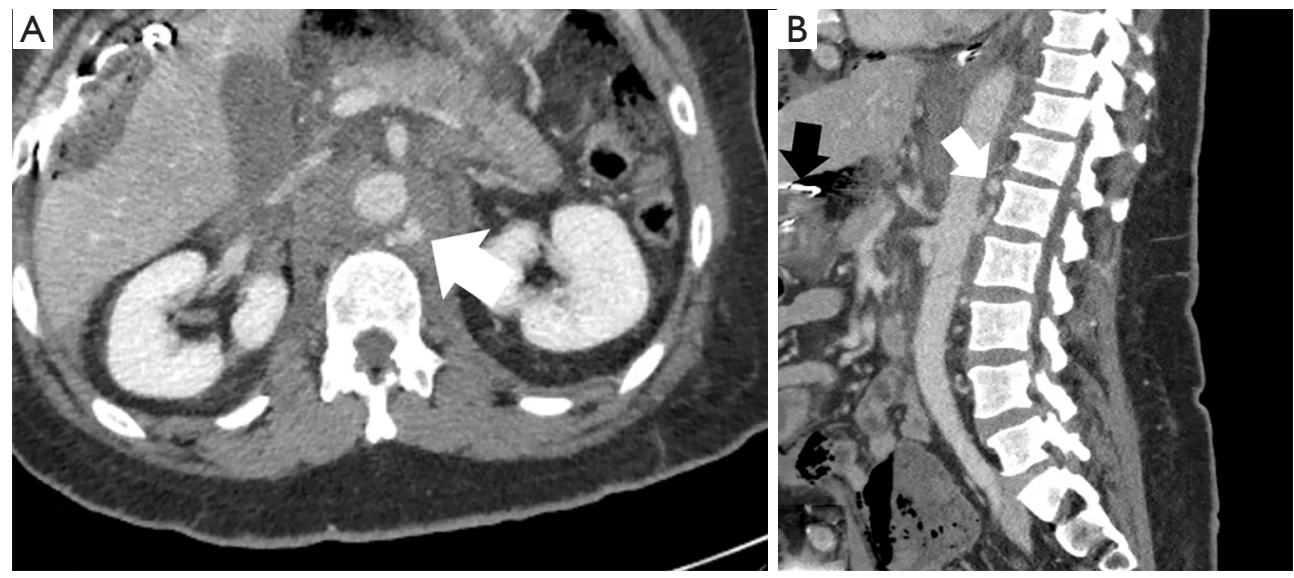

Figure 2 A patient with gunshot wounds. (A) Axial slice from a contrast-enhanced CT of the abdomen demonstrates a pseudoaneurysm of the abdominal aorta with retrocrural hematoma (white arrow) (Surgical packing material is seen adjacent to the liver); (B) sagittal reformat image from a contrast-enhanced CT of the abdomen demonstrates the pseudoaneurysm of the aorta (white arrow). A bullet fragment is seen anteriorly (black arrow). CT, computed tomography.

specific. In fact, up to $7 \%$ of chest radiographs appear normal despite underlying injury $(14,21)$. Thus, a definitive diagnosis with cross-sectional imaging should be pursued if the patient's presentation yields clinical concern.

\section{Computed tomography (CT)}

CTA is the first-line imaging modality recommended by the American College of Radiology (ACR) in evaluating for ATAI (22). Multiple prospective and retrospective studies have found that its sensitivity for ATAI approaches 100\% with a specificity above $80 \%(2,21,23-26)$. Acquisition techniques are typically institution-dependent. There are, however, certain elements that are required specifically for CTA in comparison to contrast-enhanced CT in arterial phase (27). First, CTA uses a thin-section acquisition (e.g., $2 \mathrm{~mm}$ ) that is timed with either peak arterial or venous enhancement, depending on the indication. Second, volumetric, multi-planar reconstructions are created and interpreted. Finally, 3-D renderings must be created and 

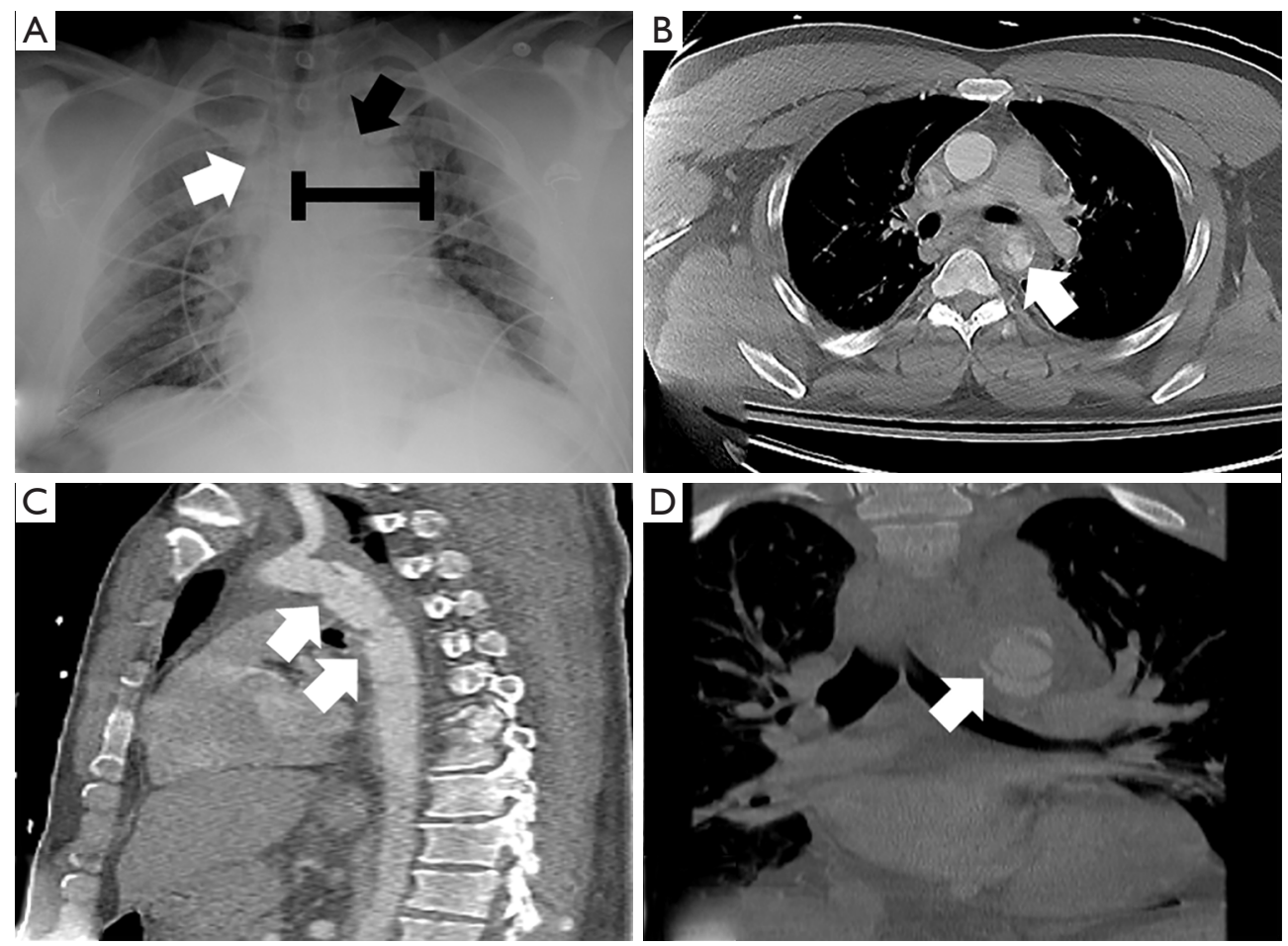

Figure 3 A patient involved in a motor vehicle crash. (A) Chest radiograph demonstrates many signs of aortic injury including widening of the mediastinum (black line), indistinct contours of the aortic arch (black arrow), and deviation of the trachea to the right (white arrow); (B) axial slice from a contrast-enhanced CT of the chest demonstrates an intimal flap and contour abnormalities (white arrow); (C) sagittal reformat image from a contrast-enhanced CT of the chest demonstrates contour abnormalities (white arrows); (D) coronal reformat image from a contrast-enhanced CT of the chest demonstrates contour abnormalities and an intimal flap (white arrow). CT, computed tomography.

interpreted. At the authors' institution, non-contrast axial images are obtained using a $5 \mathrm{~mm}$ slice thickness. Subsequently, a weight-based dose of iodinated intravenous contrast is given at a rate of $4-6 \mathrm{~mL} / \mathrm{sec}$ with the use of automatic bolus tracking and prospective gating. Axial images are then obtained at both peak arterial and portovenous enhancement using a slice thickness of $2 \mathrm{~mm}$. After image acquisition, both multi-planar reformatted images and $3-\mathrm{D}$ renderings are created.

The evaluation of a CT or CTA for ATAI should begin with a review of non-contrast images to identify a mediastinal hematoma, if present. Mediastinal hematoma is the most important indirect sign of ATAI (Figure 1). If a mediastinal hematoma is present, this should prompt a close evaluation of the periaortic fat for stranding. Preservation of a clean fat plane around the aorta makes it highly unlikely that the source of the hematoma is from aortic injury (28). Conversely, periaortic involvement of the hematoma should heighten suspicion for aortic injury and substantially reduces the false-positive rate compared to a mediastinal hematoma without periaortic involvement (28).

The direct signs of ATAI have the highest sensitivity and specificity (29). Direct signs of ATAI include pseudoaneurysm, focal contour abnormality, intimal flap, intramural hematoma, an abrupt change in aortic caliber, and contrast extravasation (Figure 3) (28). The arterial phase images need to be carefully reviewed to identify any of these findings. The sagittal plane allows for rapid assessment of the entire aorta for gross injury. It is particularly useful for identifying abnormalities that may only be visible on one or two axial slices, such as an intimal flap. Sites of relative immobility should be scrutinized, especially the attachment site for the ligamentum arteriosum, located approximately 2 centimeters from the origin of the left subclavian artery. Careful tracing of the aorta in the axial plane can reveal transmural hematoma and subtle 
contour abnormalities, including pseudoaneurysm. Active extravasation of contrast is rarely seen as these patients are usually critically unstable or expire before arrival to the hospital (14). When considering abdominal aortic injury, the evaluation is often more reliant on the detection of indirect signs. For example, the identification of thoracic or lumbar vertebral body fractures should prompt a search for aortic injury at these levels. Similarly, the retroperitoneal organs should be evaluated, given the high association between organ injury and aortic trauma (17). A meticulous search for retroperitoneal hematoma and periaortic fat stranding is also essential given that these signs are sensitive for abdominal aortic injury detection (Figure 2) $(12,17,30)$. The direct signs of abdominal aortic injury are similar to those described for thoracic aortic injury. Upon detection of one or more direct signs of aortic injury, no further diagnostic imaging should be necessary. This should prompt immediate consultation for endovascular or open repair.

An accurate diagnosis of ATAI requires an understanding of the common imaging mimics. One such example is a ductus diverticulum. In newborns, the aorta is narrowed between the origin of the left subclavian artery and ductus arteriosum. Once the ductus arteriosum is closed, flow through the aorta in this narrowed region increases and typically results in expansion. In $\sim 10 \%$ of patients, however, this narrowed region persists along with a small focal bulge below the isthmus-a ductus diverticulum (31). Differentiating a ductus diverticulum from traumatic pseudoaneurysm is critical, especially considering that most blunt aortic trauma will result in injury at this same location. Ductus diverticulum is characterized by a wide base, smooth margins, and obtuse angles between the bulging and aortic wall. Conversely, traumatic pseudoaneurysm will typically have a narrow base, irregular margins, and acute angles between the bulging and aortic wall. The presence of additional traumatic findings, including intimal flap or mediastinal hematoma, also favors pseudoaneurysm $(29,31)$. The infundibula of the brachiocephalic arteries are another anatomic structure that could be confused with a traumatic pseudoaneurysm. These infundibula typically occur at vessel origins and have a conical shape with smooth anatomic margins. The left subclavian artery is the most common arch vessel to have an infundibulum (32). Additional pitfalls include those secondary to acquisition techniques. For instance, both cardiac and respiratory motion can create contour abnormalities that may be mistaken for traumatic injury (29). Typically, such pulsation artifacts appear on both sides of the aorta and occur near the aortic root. Reviewing lung windows can make the degree of respiratory motion more apparent and allow a better determination as to whether a finding is real or an artifact. An electrocardiogram (ECG)-gated CT can be performed to eliminate cardiac motion, if necessary $(14,29)$.

\section{Magnetic resonance imaging (MRI)}

MRI has inherent disadvantages in the acute setting due to lengthy exam times, the requirement for prolonged patient cooperation, and potential MRI safety issues such as incompatible support devices or unknown implanted devices. In stable patients for which intervention is delayed, however, MRI provides remarkable anatomic detail and allows for accurate assessment of lesion severity (33). Like CT, it offers a comprehensive overview of the thorax, including the mediastinum and periaortic regions. 4-D MRI flow techniques have been used to assess aortic hemodynamics and identify sites of elevated wall stress $(34,35)$. Though there may be a role for this technique in predicting hemodynamics post-thoracic endovascular aortic repair (TEVAR), it has primarily been performed for patients with non-traumatic pathology, such as aortic aneurysm, dissection, coarctation, or valvular anomalies (34-36). Finally, MRI serves a particularly useful role in follow-up imaging in that it limits radiation exposure to patients who would otherwise obtain multiple CT exams for monitoring (33).

\section{Conventional angiography, intravascular ultrasound (IVUS), and transesophageal echocardiogram}

The historical gold standard for ATAI diagnosis is conventional angiography, with both sensitivity and specificity approaching $100 \%$ (25). In the era of multidetector CT, however, its role has been substantially limited. Currently, conventional angiography is primarily performed in the stable patient as a pre-operative planning tool for endovascular stent graft therapy (Figure 4) (14). Additionally, angiography may occasionally detect branch vessel injury that is occult on CT $(2,14)$.

Currently, the role of IVUS is primarily that of an adjunct to TEVAR. CTA frequently underestimates the true aortic diameter in younger patients due to increased aortic compliance and fluctuating hemodynamic physiology in the setting of trauma $(37,38)$. At the time of intervention, patients are likely to have received adequate volume resuscitation with resultant normalization of the aortic 

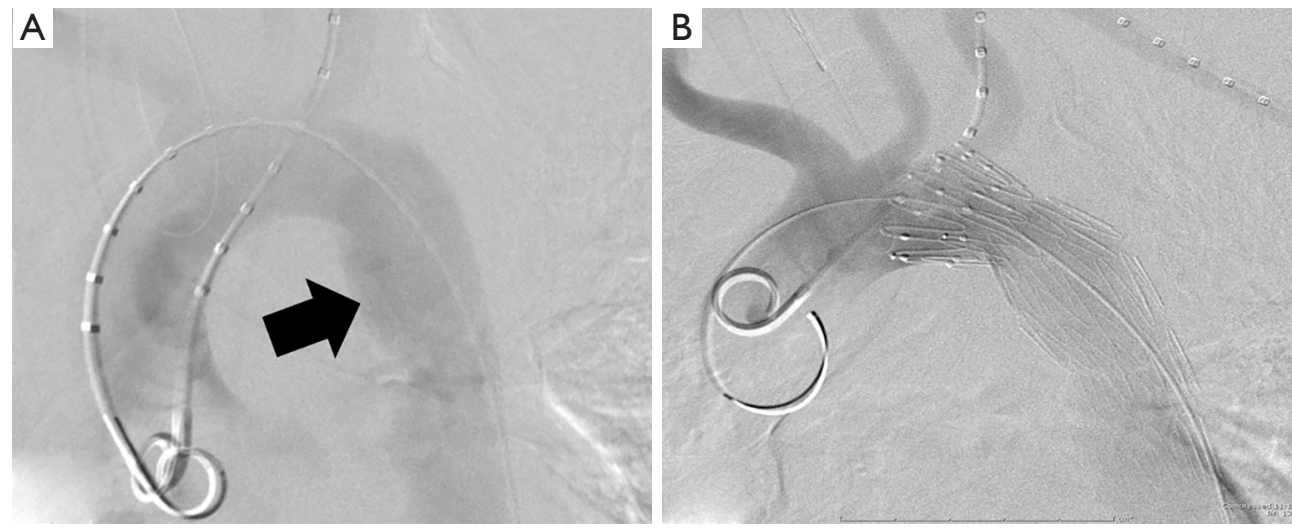

Figure 4 The same patient from Figure 3, who was involved in a motor vehicle crash. (A) DSA of the thoracic aorta during TEVAR demonstrates the contour abnormalities seen on CT in Figure 3C (black arrow); (B) DSA of the thoracic aorta after stent graft deployment. A measuring catheter used to delineate the origin of the left subclavian artery is seen on both images. DSA, digital subtraction angiography; TEVAR, thoracic endovascular aortic repair; CT, computed tomography.

diameter. Utilization of IVUS during TEVAR allows for more accurate measurement of the aortic diameter, identification of the aortic defect and potential endograft landing zones, and appropriately sized endograft selection (37-40). Sonographic findings are similar to direct CT findings including vessel wall disruption, intimal flap, pseudoaneurysm, intramural and periaortic hematoma, and complete transection $(41,42)$. As with all sonographic techniques, the diagnostic quality will depend upon the experience of the operator.

Transesophageal echocardiography (TEE) has high diagnostic performance for the detection of ATAI with sensitivity and specificity approaching $97 \%$ (43). In patients with equivocal CT or angiographic findings, TEE can be performed to clarify the diagnosis and has far greater sensitivity than both angiography and CT in detecting minor non-surgical aortic injuries (43). Finally, TEE is advantageous in that it can be performed at the bedside in unstable patients or even intraoperatively to guide surgical decisions $(14,42,43)$. Disadvantages include dependence on operator experience and poor visualization of the distal ascending aorta and proximal arch (44).

\section{Treatment}

The initial management of ATAI involves securing large bore peripheral IV access for fluid resuscitation, close monitoring of hemodynamics in an intensive care setting, and anti-impulse therapy (i.e., strict control of blood pressure and heart rate). Anti-impulse therapy is initiated to minimize propagation of the injury through the use of negative inotropic agents (beta-blockers) and antihypertensives (sodium nitroprusside or calcium channel blockers) with a goal of maintaining a systolic blood pressure of $<100 \mathrm{mmHg}$ and heart rate $<100$ beats per minute.

ATAI is graded according to the severity of injury, which, in addition to patient stability and anatomic limitations, ultimately determines the treatment approach (45). In this classification, intimal tears are a grade I injury, intramural hematomas are a grade II injury, pseudoaneuryms are a grade III injury, and free rupture is a grade IV injury. Patients with grade I injuries are low risk and may be managed expectantly given that most of these injuries heal spontaneously or remain stable. Current guidelines recommend operative repair of grade II-IV injuries (46). Severe aortic injuries (i.e., grade III-IV) should be repaired immediately. Grade II injuries can be delayed if anti-impulse therapy is instituted and there is no clinical evidence of injury progression. All hemodynamically unstable patients with suspected or proven ATAI should be taken to a hybrid operating room for immediate treatment whether endovascular or open (47). When repair is required it should take place within 24 hours of the injury (46). The vast majority of blunt injuries to the aorta occur in the thoracic aorta, making those that affect the abdominal aorta a relative rarity. Accordingly, there are no clinical practice guidelines for the treatment of blunt abdominal aortic trauma. Nevertheless, the same tenets apply to all injured areas of the aorta. 


\section{Non-operative management}

Non-operative management of ATAI consists of aggressive anti-impulse therapy with inpatient monitoring and surveillance imaging. Currently, the Society of Vascular Surgeons (SVS) recommends a non-operative approach be instituted for patients with Grade I injuries (46). As mentioned, injury progression in such cases is rare (48-50). Since publication of these guidelines, several retrospective studies have shown that non-operative management of Grade II injuries is both feasible and safe with good intermediate outcomes $(48,51,52)$. The most serious concern with non-operative management is progression of an intimal tear to chronic dissection, pseudoaneurysm, or aortic rupture. Two case series have demonstrated low rates of progression and aortic-specific mortality among appropriately selected patients $(48,53)$. Yet, Mosquera et al. reported rates of post-traumatic pseudoaneurysm and aortic rupture at $27.5 \%$ and $87.5 \%$, respectively, within their non-operative cohort of which $67 \%$ were grade I and II injuries (54). Although many patients can be managed without TEVAR, there are often concurrent traumatic brain injuries, which introduces competing interests with relation to blood pressure goals. Early TEVAR can allow for relaxation of the blood pressure goals and provide the opportunity for intentional hypertension should it become necessary for brain injuries. Patients with ATAI who are managed non-operatively require long-term follow-up until radiographic evidence of injury resolution is obtained. There is currently no consensus on an optimal surveillance schedule. At the authors' institution, outpatient imaging is obtained within 1 month after repair, with further followup imaging dictated by the appearance of the repair on the initial examination. Often, repeat CTA is warranted each year, but the authors often extend follow-up to every 2 years if stability of the repair is seen for the first 2 years.

\section{Endovascular repair}

The therapeutic paradigm for ATAI has shifted toward endovascular repair, when possible, as TEVAR is associated with significantly lower rates of paraplegia, stroke, and mortality (Figure 5) (55-57). Anatomic criteria for TEVAR include a healthy 2 centimeters of aorta at the proximal and distal landing zones, a proximal landing zone diameter of less than or equal to $42 \mathrm{~mm}$ appropriate access vessels, minimal aortic calcification, tortuosity, or thrombus, especially at the anticipated landing zones. Percutaneous arterial access using the "pre-close" method is reasonable and has a high degree of success (58). Open femoral artery cut down may facilitate accessing small caliber vessels in young patients or those with significant atherosclerosis. Pelvic or lower extremity fixation devices may also be cumbersome from an operative standpoint. Open retroperitoneal exposure with direct cannulation of the common iliac artery via a Dacron conduit or the abdominal aorta can be performed selectively if the iliofemoral vessels are especially small, diseased, or in spasm.

For patients with more proximal injuries, hybrid options include supra-aortic debranching or brachiocephalic vessel proximalization with arch endografting versus standard open repair techniques, although this is rarely necessary. If needed, coverage of the left subclavian artery is generally well-tolerated. In the authors' experience, selective revascularization of the left subclavian artery is used in cases of left vertebral dominance or if clinical signs of arterial insufficiency arise. Generally, if arm ischemia occurs, it is not severe and can be treated non-urgently with a left carotid-subclavian bypass or subclavian-tocarotid transposition. It is worth noting, that spinal cord ischemia risk does increase with left subclavian coverage in combination with extended thoracic aortic coverage.

The rarity of blunt abdominal aortic injury limits the available data on endovascular repair, but its feasibility can be extrapolated from endovascular aortic repair (EVAR) outcomes for the treatment of abdominal aortic aneurysms which showed improved short and intermediate-term outcomes compared to open surgery $(59,60)$. The anatomic suitability for EVAR mirrors that of TEVAR. If anatomic inconsistencies arise, intraoperative IVUS may be of use.

Finally, cerebral spinal fluid drainage is generally not necessary in patients with ATAI. However, spinal cord ischemia can occur, and the authors would recommend an emergent spinal drain, immediate revascularization of the left subclavian artery if it was covered during the repair, and rescue maneuvers including increasing the hematocrit to $>30$ and permissive hypertension if successful repair has been achieved.

\section{Open repair}

Despite a long history of use (1) and improvements in surgical techniques, open repair for ATAI is associated with high rates of morbidity and mortality (45). Thus, open repair is now reserved for patients with unfavorable anatomy for endovascular repair. When used, the operative approach 

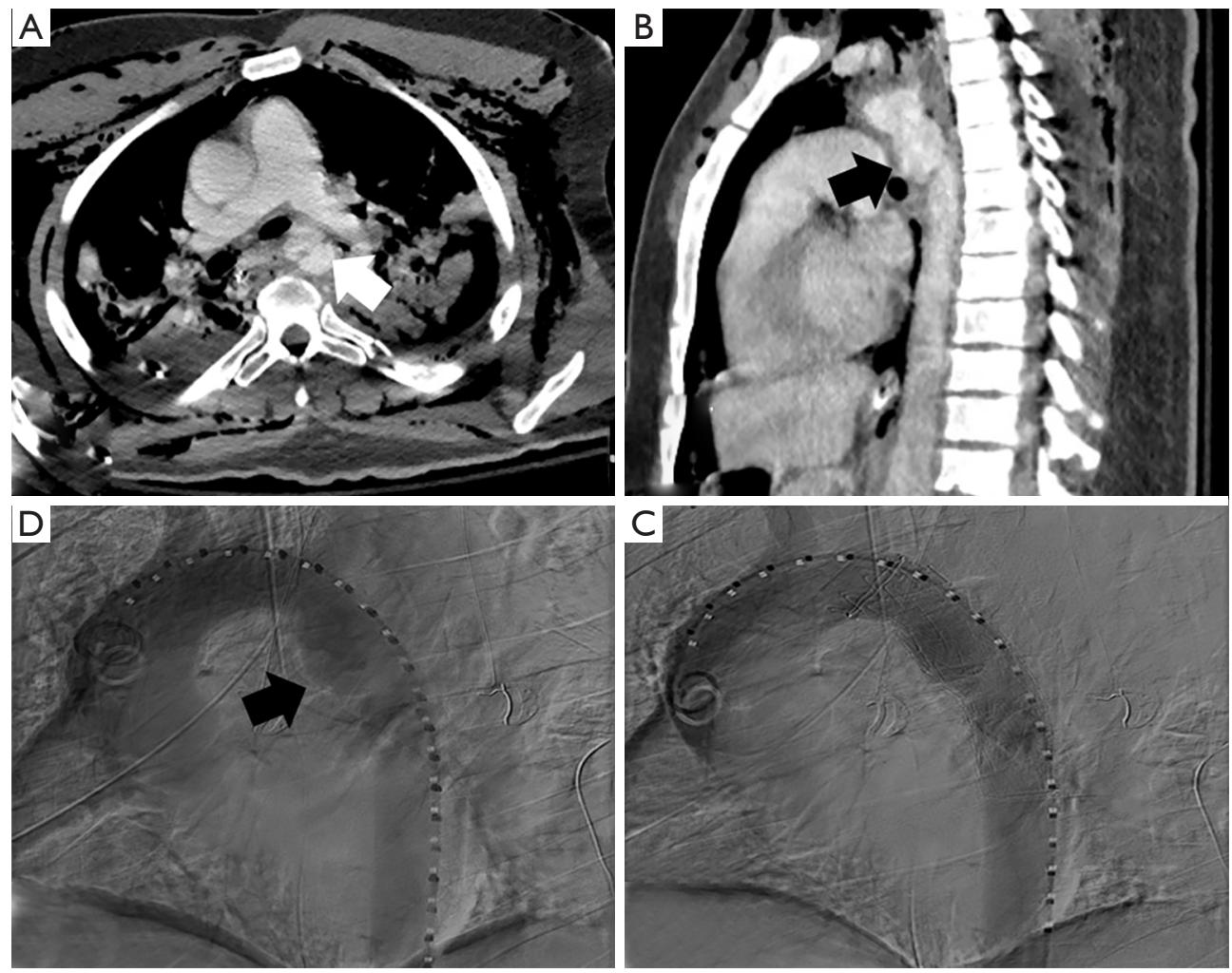

Figure 5 A patient involved in a motor vehicle crash. (A) Axial slice from a contrast-enhanced CT of the chest demonstrates contour abnormalities of the descending thoracic aorta (white arrow). Subcutaneous emphysema and a right chest tube are present; (B) sagittal reformat from a contrast-enhanced CT of the chest demonstrates contour abnormalities of the descending thoracic aorta (black arrow). Subcutaneous emphysema is present; (C) DSA of the thoracic aorta prior to TEVAR demonstrates the contour abnormalities seen on CT (black arrow); (D) DSA of the thoracic aorta after stent graft deployment. CT, computed tomography; DSA, digital subtraction angiography; TEVAR, thoracic endovascular aortic repair.

is contingent upon the location of injury. Injuries proximal to the left subclavian artery are accessed through a median sternotomy with cardiopulmonary bypass (CPB) with cardioplegic arrest, with or without circulatory arrest. Full heparinization is necessary for CPB and bleeding risk in the trauma patient must be considered. In these cases, ascending or transverse arch injury typically requires replacement of the aorta and/or brachiocephalic vessels with Dacron graft material as endovascular repair is limited for proximal arch pathology. Proximal descending aortic pathology can be treated in conjunction with open ascending or transverse arch repair with placement of a frozen elephant trunk graft, although this would be unusual in the trauma population. Injuries to the descending thoracic aorta are exposed with a high posterolateral thoracotomy versus standard thoracoabdominal incision with single lung ventilation for optimal exposure. A laparotomy incision for intraperitoneal or retroperitoneal exposure exposes the abdominal aorta. A variety of techniques can be instituted for repair the aorta distal to the left subclavian such as clamp and sew, or those offering adjunctive distal aortic perfusion such as partial peripheral bypass, full CPB via left heart cannulation, or axillary-femoral bypass.

\section{Complications}

Non-operative, endovascular, and open approaches are all associated with major adverse events. Historically, open repair was associated with mortality and paraplegia rates as high as $28 \%$ and $16 \%$, respectively (46). Large incisions also increase the risk of surgical bleeding, infection, prolonged intubation, and extended length of stay. Although endovascular repair has decreased the rate of these complications, challenges associated with these 
new techniques and technology have arisen $(56,61)$. The most common complication after endovascular repair is endoleak, with reported incidence approaching $15 \%$ (62-64). Three types of endoleak are considered in the setting of aortic trauma and are similar to those described for non-traumatic aneurysm repair, with type I (inadequate sealing at graft end) being the most commonly reported (57,64-66). Management depends on the severity of the findings and ranges from conservative follow-up for spontaneous resolution to immediate endovascular or surgical repair.

Endograft collapse can be either partial or complete and is associated with high morbidity and mortality $(56,64,67)$. Patients are predisposed to this complication based on anatomic factors, including sharp aortic angulation and insufficient distance between the cranial end of the graft and the left subclavian artery origin (62). This results in poor apposition of the endograft to the native aortic wall, which increases the risk for collapse. Treatment depends on the severity of collapse and ranges from surveillance to deployment of a second endograft or open repair $(62,64)$.

Endograft infection is a rare complication with high morbidity and mortality, potentially resulting in mycotic aneurysm formation or sepsis with multisystem organ failure $(68,69)$. If the infection does not resolve with conservative antibiotic treatment, open repair with placement of a polyester fabric graft is often required $(64,68-70)$.

Outright failure of the endograft itself is a rare complication of TEVAR $(64,71,72)$. Fracture of the metallic framework can be recognized on CT by sharp angulations of the framework. Irregularity of the graft material may be suggestive of its disruption. In either case, a type III endoleak will usually accompany these findings if the defect is clinically significant $(71,72)$.

Finally, the initial endograft may not exclude the entirety of aortic injury. This is usually identified with intraprocedural aortography, and a second overlapping stent is deployed (64). In rare instances, the endograft can migrate and lead to re-exposure of the aortic defect. With the site of injury exposed to systemic arterial pressures, these patients are at an elevated risk for rupture (73). With either circumstance, immediate intervention is required to prevent exacerbation of the aortic injury $(64,73)$.

\section{Conclusions}

ATAI is an injury with high fatality rates. For patients who survive the initial injury, rapid detection with radiography and CTA are critical for diagnosis and procedural planning. Appropriately selected patients with low grade injuries may be managed non-operatively. When treatment is required, endovascular approaches are preferred due to their high clinical success and low rates of complications.

\section{Acknowledgments}

The authors would like to acknowledge Dr. Keith Quencer for graciously providing images for Figures 1,3,4.

Funding: None.

\section{Footnote}

Provenance and Peer Review: This article was commissioned by the Guest Editor (Dr. Keith Bertram Quencer) for the series "Endovascular interventions in trauma" published in Annals of Translational Medicine. The article was sent for external peer review organized by the Guest Editor and the editorial office.

Conflicts of Interest: All authors have completed the ICMJE uniform disclosure form (available at http://dx.doi. org/10.21037/atm-20-3172). The series "Endovascular interventions in trauma" was commissioned by the editorial office without any funding or sponsorship. Dr. KWE reports personal fees from Terumo, personal fees from Cryolife, personal fees from Medtronic, outside the submitted work. Dr. AWB reports personal fees from Terumo, personal fees from Cryolife, personal fees from Medtronic, personal fees from Cook, grants from Cook, outside the submitted work. Dr. AJG reports personal fees from BTG, personal fees from Terumo, grants from Penumbra, outside the submitted work. The other authors have no other conflicts of interest to declare.

Ethical Statement: The authors are accountable for all aspects of the work in ensuring that questions related to the accuracy or integrity of any part of the work are appropriately investigated and resolved.

Open Access Statement: This is an Open Access article distributed in accordance with the Creative Commons Attribution-NonCommercial-NoDerivs 4.0 International License (CC BY-NC-ND 4.0), which permits the noncommercial replication and distribution of the article with the strict proviso that no changes or edits are made and the original work is properly cited (including links to both the 
formal publication through the relevant DOI and the license). See: https://creativecommons.org/licenses/by-nc-nd/4.0/.

\section{References}

1. Parmley LF, Mattingly TW, Manion WC, et al. Nonpenetrating traumatic injury of the aorta. Circulation 1958;17:1086-101.

2. Steenburg SD, Ravenel JG. Acute traumatic thoracic aortic injuries: experience with 64-MDCT. AJR Am J Roentgenol 2008;191:1564-9.

3. Williams JS, Graff JA, Uku JM, et al. Aortic injury in vehicular trauma. Ann Thorac Surg 1994;57:726-30.

4. Schulman CI, Carvajal D, Lopez PP, et al. Incidence and crash mechanisms of aortic injury during the past decade. J Trauma 2007;62:664-7.

5. Neschis DG, Scalea TM, Flinn WR, et al. Blunt aortic injury. N Engl J Med 2008;359:1708-16.

6. Horton TG, Cohn SM, Heid MP, et al. Identification of trauma patients at risk of thoracic aortic tear by mechanism of injury. J Trauma 2000;48:1008-13.

7. Dischinger PC, Cushing BM, Kerns TJ. Injury patterns associated with direction of impact: drivers admitted to trauma centers. J Trauma 1993;35:454-8.

8. Richens D, Field M, Neale M, et al. The mechanism of injury in blunt traumatic rupture of the aorta. Eur J Cardiothorac Surg 2002;21:288-93.

9. Baqué P, Serre T, Cheynel N, et al. An experimental cadaveric study for a better understanding of blunt traumatic aortic rupture. J Trauma 2006;61:586-91.

10. Cohen AM, Crass JR, Thomas HA, et al. CT evidence for the "osseous pinch" mechanism of traumatic aortic injury. AJR Am J Roentgenol 1992;159:271-4.

11. Crass JR, Cohen AM, Motta AO, et al. A proposed new mechanism of traumatic aortic rupture: the osseous pinch. Radiology 1990;176:645-9.

12. Mellnick VM, McDowell C, Lubner M, et al. CT features of blunt abdominal aortic injury. Emerg Radiol 2012;19:301-7.

13. Williams DM, Simon HJ, Marx MV, et al. Acute traumatic aortic rupture: intravascular US findings. Radiology 1992;182:247-9.

14. Steenburg SD, Ravenel JG, Ikonomidis JS, et al. Acute traumatic aortic injury: imaging evaluation and management. Radiology 2008;248:748-62.

15. Lundervall J. The mechanism of traumatic rupture of the aorta. Acta Pathol Microbiol Scand 1964;62:34-46.

16. Shalhub S, Starnes BW, Tran NT, et al. Blunt abdominal aortic injury. J Vasc Surg 2012;55:1277-85.

17. Tsai R, Raptis D, Raptis C, et al. Traumatic abdominal aortic injury: clinical considerations for the diagnostic radiologist. Abdom Radiol (NY) 2018;43:1084-93.

18. Merrill WH, Lee RB, Hammon JW, Jr., et al. Surgical treatment of acute traumatic tear of the thoracic aorta. Ann Surg 1988;207:699-706.

19. Kram HB, Wohlmuth DA, Appel PL, et al. Clinical and radiographic indications for aortography in blunt chest trauma. J Vasc Surg 1987;6:168-76.

20. Sefczek DM, Sefczek RJ, Deeb ZL. Radiographic signs of acute traumatic rupture of the thoracic aorta. AJR Am J Roentgenol 1983;141:1259-62.

21. Fabian TC, Davis KA, Gavant ML, et al. Prospective study of blunt aortic injury: helical CT is diagnostic and antihypertensive therapy reduces rupture. Ann Surg 1998;227:666-76.

22. Demehri S, Rybicki FJ, Desjardins B, et al. ACR Appropriateness Criteria $\left({ }^{\circledR}\right)$ blunt chest trauma--suspected aortic injury. Emerg Radiol 2012;19:287-92.

23. Gavant ML, Menke PG, Fabian T, et al. Blunt traumatic aortic rupture: detection with helical CT of the chest. Radiology 1995;197:125-33.

24. Dyer DS, Moore EE, Ilke DN, et al. Thoracic aortic injury: how predictive is mechanism and is chest computed tomography a reliable screening tool? A prospective study of 1,561 patients. J Trauma 2000;48:673-82.

25. Wintermark M, Wicky S, Schnyder P. Imaging of acute traumatic injuries of the thoracic aorta. Eur Radiol 2002;12:431-42.

26. Mirvis SE, Shanmuganathan K, Miller BH, et al. Traumatic aortic injury: diagnosis with contrast-enhanced thoracic CT--five-year experience at a major trauma center. Radiology 1996;200:413-22.

27. Chung JH, Cox CW, Mohammed TL, et al. ACR appropriateness criteria blunt chest trauma. J Am Coll Radiol 2014;11:345-51.

28. Fishman JE, Nuñez D Jr, Kane A, et al. Direct versus indirect signs of traumatic aortic injury revealed by helical CT: performance characteristics and interobserver agreement. AJR Am J Roentgenol 1999;172:1027-31.

29. Hahn LD, Prabhakar AM, Zucker EJ. Cross-sectional imaging of thoracic traumatic aortic injury. Vasa 2019;48:6-16.

30. de Mestral C, Dueck AD, Gomez D, et al. Associated injuries, management, and outcomes of blunt abdominal aortic injury. J Vasc Surg 2012;56:656-60.

31. Hyung Ann J, Young Kim E, Mi Jeong Y, et al. 
Morphologic evaluation of ductus diverticulum using multi - detector computed tomography: comparison with traumatic pseudoaneurysm of the aortic isthmus. Iran J Radiol 2016;13:e38016.

32. Fisher RG, Sanchez-Torres M, Whigham CJ, et al. "Lumps" and "bumps" that mimic acute aortic and brachiocephalic vessel injury. Radiographics 1997;17:825-34.

33. Fattori R, Celletti F, Bertaccini P, et al. Delayed surgery of traumatic aortic rupture. Role of magnetic resonance imaging. Circulation 1996;94:2865-70.

34. Markl M, Frydrychowicz A, Kozerke S, et al. 4D flow MRI. J Magn Reson Imaging 2012;36:1015-36.

35. Adriaans BP, Wildberger JE, Westenberg JJM, et al. Predictive imaging for thoracic aortic dissection and rupture: moving beyond diameters. Eur Radiol 2019;29:6396-404.

36. Pirola S, Guo B, Menichini C, et al. 4-D flow MRIbased computational analysis of blood flow in patientspecific aortic dissection. IEEE Trans Biomed Eng 2019;66:3411-9.

37. Ceja-Rodriguez M, Realyvasquez A, Galante J, et al. Differences in aortic diameter measurements with intravascular ultrasound and computed tomography after blunt traumatic aortic injury. Ann Vasc Surg 2018;50:148-53.

38. Shi Y, Tsai PI, Wall MJ, Jr., et al. Intravascular ultrasound enhanced aortic sizing for endovascular treatment of blunt aortic injury. J Trauma Acute Care Surg 2015;79:817-21.

39. Han SM, Elsayed RS, Ham SW, et al. Comparison of intravascular ultrasound- and centerline computed tomography-determined aortic diameters during thoracic endovascular aortic repair. J Vasc Surg 2017;66:1184-91.

40. Wallace GA, Starnes BW, Hatsukami TS, et al. Intravascular ultrasound is a critical tool for accurate endograft sizing in the management of blunt thoracic aortic injury. J Vasc Surg 2015;61:630-5.

41. Uflacker R, Horn J, Phillips G, et al. Intravascular sonography in the assessment of traumatic injury of the thoracic aorta. AJR Am J Roentgenol 1999;173:665-70.

42. Patel NH, Hahn D, Comess KA. Blunt chest trauma victims: role of intravascular ultrasound and transesophageal echocardiography in cases of abnormal thoracic aortogram. J Trauma 2003;55:330-7.

43. Cinnella G, Dambrosio M, Brienza N, et al. Transesophageal echocardiography for diagnosis of traumatic aortic injury: an appraisal of the evidence. J Trauma 2004;57:1246-55.
44. Konstadt SN, Reich DL, Quintana C, et al. The ascending aorta: how much does transesophageal echocardiography see? Anesth Analg 1994;78:240-4.

45. Azizzadeh A, Keyhani K, Miller CC 3rd, et al. Blunt traumatic aortic injury: initial experience with endovascular repair. J Vasc Surg 2009;49:1403-8.

46. Lee WA, Matsumura JS, Mitchell RS, et al. Endovascular repair of traumatic thoracic aortic injury: clinical practice guidelines of the Society for Vascular Surgery. J Vasc Surg 2011;53:187-92.

47. ATLS Subcommittee; American College of Surgeons' Committee on Trauma; International ATLS working group. Advanced trauma life support (ATLS®): the ninth edition. J Trauma Acute Care Surg 2013;74:1363-6.

48. Osgood MJ, Heck JM, Rellinger EJ, et al. Natural history of grade I-II blunt traumatic aortic injury. J Vasc Surg 2014;59:334-41.

49. Kidane B, Abramowitz D, Harris JR, et al. Natural history of minimal aortic injury following blunt thoracic aortic trauma. Can J Surg 2012;55:377-81.

50. Starnes BW, Lundgren RS, Gunn M, et al. A new classification scheme for treating blunt aortic injury. J Vasc Surg 2012;55:47-54.

51. Rabin J, DuBose J, Sliker CW, et al. Parameters for successful nonoperative management of traumatic aortic injury. J Thorac Cardiovasc Surg 2014;147:143-9.

52. Sandhu HK, Leonard SD, Perlick A, et al. Determinants and outcomes of nonoperative management for blunt traumatic aortic injuries. J Vasc Surg 2018;67:389-98.

53. Caffarelli AD, Mallidi HR, Maggio PM, et al. Early outcomes of deliberate nonoperative management for blunt thoracic aortic injury in trauma. J Thorac Cardiovasc Surg 2010;140:598-605.

54. Mosquera VX, Marini M, Lopez-Perez JM, et al. Role of conservative management in traumatic aortic injury: comparison of long-term results of conservative, surgical, and endovascular treatment. J Thorac Cardiovasc Surg 2011;142:614-21.

55. Estrera AL, Miller CC, 3rd, Guajardo-Salinas G, et al. Update on blunt thoracic aortic injury: fifteen-year single-institution experience. J Thorac Cardiovasc Surg 2013;145:S154-8.

56. Demetriades D, Velmahos GC, Scalea TM, et al. Operative repair or endovascular stent graft in blunt traumatic thoracic aortic injuries: results of an American Association for the Surgery of Trauma Multicenter Study. J Trauma 2008;64:561-70.

57. Tang GL, Tehrani HY, Usman A, et al. Reduced mortality, 
paraplegia, and stroke with stent graft repair of blunt aortic transections: a modern meta-analysis. J Vasc Surg 2008;47:671-5.

58. Lee WA, Brown MP, Nelson PR, et al. Total percutaneous access for endovascular aortic aneurysm repair ("Preclose" technique). J Vasc Surg 2007;45:1095-101.

59. Bulder RMA, Bastiaannet E, Hamming JF, et al. Metaanalysis of long-term survival after elective endovascular or open repair of abdominal aortic aneurysm. Br J Surg 2019;106:523-33.

60. United Kingdom EVAR Trial Investigators, Greenhalgh RM, Brown LC, et al. Endovascular versus open repair of abdominal aortic aneurysm. N Engl J Med 2010;362:1863-71.

61. Amabile P, Collart F, Gariboldi V, et al. Surgical versus endovascular treatment of traumatic thoracic aortic rupture. J Vasc Surg 2004;40:873-9.

62. Neschis DG, Moainie S, Flinn WR, et al. Endograft repair of traumatic aortic injury-a technique in evolution: a single institution's experience. Ann Surg 2009;250:377-82.

63. Xenos ES, Abedi NN, Davenport DL, et al. Meta-analysis of endovascular vs open repair for traumatic descending thoracic aortic rupture. J Vasc Surg 2008;48:1343-51.

64. Morgan TA, Steenburg SD, Siegel EL, et al. Acute traumatic aortic injuries: posttherapy multidetector CT findings. Radiographics 2010;30:851-67.

65. Moainie SL, Neschis DG, Gammie JS, et al. Endovascular stenting for traumatic aortic injury: an emerging new standard of care. Ann Thorac Surg 2008;85:1625-9;

Cite this article as: Brown SR, Still SA, Eudailey KW, Beck AW, Gunn AJ. Acute traumatic injury of the aorta: presentation, diagnosis, and treatment. Ann Transl Med 2021;9(14):1193. doi: 10.21037/atm-20-3172 discussion 1629-30.

66. Orend KH, Kotsis T, Scharrer-Pamler R, et al. Endovascular repair of aortic rupture due to trauma and aneurysm. Eur J Vasc Endovasc Surg 2002;23:61-7.

67. Neschis DG, Moaine S, Gutta R, et al. Twenty consecutive cases of endograft repair of traumatic aortic disruption: lessons learned. J Vasc Surg 2007;45:487-92.

68. Heyer KS, Modi P, Morasch MD, et al. Secondary infections of thoracic and abdominal aortic endografts. J Vasc Interv Radiol 2009;20:173-9.

69. Orton DF, LeVeen RF, Saigh JA, et al. Aortic prosthetic graft infections: radiologic manifestations and implications for management. Radiographics 2000;20:977-93.

70. Brown KE, Eskandari MK, Matsumura JS, et al. Short and midterm results with minimally invasive endovascular repair of acute and chronic thoracic aortic pathology. J Vasc Surg 2008;47:714-22.

71. Urgnani F, Lerut P, Da Rocha M, et al. Endovascular treatment of acute traumatic thoracic aortic injuries: a retrospective analysis of 20 cases. J Thorac Cardiovasc Surg 2009;138:1129-38.

72. Lachat M, Pfammatter T, Witzke H, et al. Acute traumatic aortic rupture: early stent-graft repair. Eur J Cardiothorac Surg 2002;21:959-63.

73. White GH, Yu W, May J, et al. Endoleak as a complication of endoluminal grafting of abdominal aortic aneurysms: classification, incidence, diagnosis, and management. J Endovasc Surg 1997;4:152-68. 